\title{
BRILLO BOX OU SÓ SABÃO? O QUE DEWEY DIRIA SOBRE OS INDISCERNIIVEIS?
}

\author{
Thiago Barros Gomes \\ Doutorando em Filosofia pela UFMG \\ $\mathrm{CNPq}$
}

\begin{abstract}
Resumo: Neste ensaio analiso o uso que a estética filosófica faz dos indiscerníveis, sobretudo na forma defendida por Arthur Danto. O objetivo é pensar uma resposta ao problema dos indiscerníveis a partir da estética pragmatista de John Dewey.

Palavras-chave: Dewey, Danto, Estética pragmatista.
\end{abstract}

Clive Bell, em A Hipótese Estética, de 1914, relata o seguinte:

Tenho um amigo dotado de um intelecto penetrante como uma broca que, embora seu interesse por estética, nunca poderá ser acusado de ter tido uma única emoção estética ao longo de seus quase quarenta anos de vida. Deste modo, não dispondo de uma faculdade que the permita distinguir uma obra de arte de um serrote, é capaz de acumular uma pirâmide de argumentos incontestáveis acerca da hipótese de um serrote ser uma obra de artel.

Alguns anos depois, já em 1917, a hipótese proposta pelo amigo de Bell seria testada por Marcel Duchamp, em sua obra Fonte. Um mictório tão comum como qualquer outro pendurado nos sanitários masculinos, retirado de sua posição natural e assinado com R. Mutt. Décadas depois Andy Warhol levaria essa possibilidade ao extremo. Alguns diriam que em Duchamp ainda há alguma alteração material que distinguiria a Fonte de um objeto comum, e que

1 CLIVE, B. “A Hipótese Estética”. Tradução: Vítor Silva. In: D'OREY, C. (Org.) O que é a arte? Uma perspectiva analítica. Lisboa, Dinalivro, 2007 (p. 28). 
Warhol foi quem testou a hipótese de fato. Outros que Duchamp o fez possível e que, sem este antecessor, Warhol não seria capaz de fazer o que fez, de criar o que criou. A paternidade ainda é objeto de disputa. Mas o filho é adotado por muitos. Afinal, Duchamp ou Warhol? Qual dos dois deu origem ao famigerado e difundido imbróglio que hoje conhecemos e denominamos de problemas dos pares de objetos indiscerníveis? O que é importante notar é que hipótese de "um serrote ser uma obra de arte" não só foi comprovada pela história da arte, como também filósofos contemporâneos de "intelecto penetrante como uma broca" têm utilizado desta hipótese para construir teorias que explicariam a razão pela qual um serrote pode ser uma obra de arte.

Jerome Stolnitz, em seu artigo "A Atitude Estética", pergunta: "Podemos dizer que uma zona de bairros degradados, sujos e miseráveis é 'estética'? E que dizer de coisas tão pouco estimulantes e tão maçadoras, como produtos empilhados, fila após fila, num armazém, ou, já agora, uma lista telefônica"?2 Stolnitz desloca a questão estética do objeto para o sujeito que o apreende. Para ele podemos apreender ou perceber qualquer objeto de um modo específico, e esse modo específico é capaz de tornar qualquer objeto num objeto estético. Para Stolnitz o serrote seria arte porque ele foi criado intencionalmente com a capacidade de suscitar atenção desinteressada e complacente, um tipo de atenção que é descrita em contraste com a atenção interessada e corriqueira.

Já George Dickie termina seu artigo "O que é a arte?" afirmando que "pode-se fazer uma obra de arte de uma orelha de porco, mas isso não a transforma necessariamente numa bolsa de seda" 3 , e com isso ele pretende separar o problema da definição da arte das questões da razão pela qual valorizamos a arte.

Porém o mais paradigmático e famoso uso da "hipótese do serrote ser uma obra de arte" foi apresentado em 1961, por Arthur Danto, em seu artigo "O Mundo da Arte", no qual defende que:

\footnotetext{
2 STOLNITZ, J. “A Atitude Estética”. Tradução: Vítor Silva. In: D'OREY, C. (Org.) O que é a arte? Uma perspectiva analítica. Lisboa, Dinalivro, 2007 (p. 45).

3 DICKIE, G. "O que é a Arte?". Tradução: Vítor Silva. In: D'OREY, C. (Org.) O que é a arte? Uma perspectiva analítica. Lisboa, Dinalivro, 2007 (p.18).
} 
Em última análise, aquilo que distingue uma caixa de cera Brillo de uma obra de arte que consiste numa Caixa de Brillo é uma certa teoria. É a teoria que a leva ao mundo da arte e a impede de se reduzir ao objeto real que é (...). É claro que, sem a teoria, é improvável que a vejamos como arte e, a fim de a vermos como parte do mundo da arte temos de dominar uma série de teorias de arte (...) 4(DANTO, 2007, p. 94).

Se Stolnitz contrasta as percepções, Danto volta sua atenção para o objeto e contrasta obras de arte e objetos comuns fisicamente indiscerníveis para determinar o que é arte. Voltaremos a Danto mais a frente.

Outro cenário que envolve, pelo menos, o contraste entre objetos comuns e obras de arte foi utilizado em defesa da indefinibilidade da arte. Segundo W. E. Kennick,

Somos capazes de separar aqueles objetos que são obras de arte daqueles que não o são porque conhecemos o português; isto é, sabemos como usar corretamente a palavra "arte" e aplicar a frase "obra de arte". (...) [S]e alguém é capaz de usar a palavra "arte" ou a frase "obra de arte" corretamente, em todos os tipos de contexto e nos tipos certos de ocasiões, ele sabe "o que a arte é", e nenhuma fórmula no mundo o tornará mais sábio 5 .

Kennick elabora um experimento mental para defender o caráter intuitivo do nosso reconhecimento de obras de arte.

Imagine um imenso depósito cheio de todos os tipos de coisas pinturas de vários gêneros, partituras musicais para sinfonias, danças e hinos, máquina, barcos, casas, igrejas e tempos, estátuas, vasos, livros de poesia e prosa, árvores, pedras, instrumentos musicais. Agora instruímos a alguém entrar no depósito e retirar todas as obras de arte que lá contém. Ele será capaz de fazer isso com um sucesso razoável, apesar do fato de que, como até mesmo os estetas devem admitir, ele não possui

4 DANTO, A. C. "O Mundo da Arte”. Tradução: Vítor Silva. In: D'OREY, C. (Org.) O que é a arte? Uma perspectiva analítica. Lisboa, Dinalivro, 2007 (p. 94).

5 KENNICK, W. E. "Does tradicional aesthetics rest on a mistake?". Mind Vol. LXVII n. 267 (1958), p. 321 (Tradução nossa). 
qualquer definição satisfatória de arte em termos de denominador comum, pois nenhuma definição foi encontrada. Agora imagine que a mesma pessoa seja enviada para retirar todos os objetos com Forma Significante, ou todos os objetos de Expressão. Certamente ela ficaria desconcertada; ela conhece uma obra de arte quando vê uma, mas tem pouca ou nenhuma ideia do que procurar quando lhe pedem para trazer um objeto que possui Forma Significante 6.

Para Kennick, o homem enviado ao depósito conseguiria retirar dele todas as obras de arte e separá-las dos objetos comuns, porque ele domina o conceito de arte em diversos usos da "arte", e da frase "obra de arte". Dessa forma, Kennick chega mais próximo do que podemos imaginar ser o modo como Wittgenstein explica a arte. Note que essa abordagem, diferentemente da de Morris Weitz7, não requer semelhança física, mas uso.

Danto, contudo, nos pede para imaginar outro depósito exatamente igual ao de Kennick, porém o que é arte num depósito não o é no outro, e vice-versa. Assim, o conjunto das obras de arte provenientes do depósito de Kennick é indiscernível do conjunto dos objetos comuns do depósito de Danto. Se pedirmos ao mesmo homem que retirou as obras de arte do depósito de Kennick para retirar as obras do depósito de Danto, esse homem certamente não terá o mesmo êxito. E se por acaso esse homem vier a fazer escolhas certas, isso certamente parecerá coincidência. Ser capaz de usar os termos "arte" ou "obra de arte" adequadamente, não ajudará o homem do depósito de Danto a distinguir objetos ontologicamente distintos, mas perceptivelmente indiscerníveis. Para Danto;

A hipótese de um segundo depósito é uma arma poderosíssima para lançar por terra toda análise do conceito de arte que pressuponha a relevância da capacidade de reconhecimento. Refuta, por exemplo, a ideia de que seja possível identificar obras de arte mediante a processos indutivos, emulação de

6 KENNICK, W. E. "Does tradicional aesthetics rest on a mistake?". Mind Vol. LXVII n. 267 (1958), p. 321 (Tradução nossa).

7 WEITZ, M. "O Papel da Teoria na Estética”. Tradução: Vítor Silva. In: D'OREY, C. (Org.) O que é a arte? Uma perspectiva analítica. Lisboa, Dinalivro, 2007 (p. 61-78). 
alguém que sabe reconhecê-las ou por algum tipo de enumeração simples. Siga um homem que está percorrendo o depósito e preste a atenção nas coisas que ele escolhe; depois vá ao segundo depósito e pegue exatamente as mesmas coisas: embora as duas listas combinem, o homem que você imitou terá escolhido as obras de arte, e você, as coisas que fazem parte do complemento dessa classe de objetos 8 .

Segundo Danto, os exemplos de reconhecimento de obras de arte oferecidos por Weitz e Kennick só são possíveis em período de estabilidade artística, quando determinadas práticas e estilos já estão alicerçados entre nós e, por isso, podemos fazer generalização desse tipo.

A hipótese do segundo depósito é considerada por Danto uma arma poderosíssima, pois esta é a arma que ele usa em suas disputas filosóficas: seja para objetar as teorias essencialistas tradicionais e as teorias da indefinibilidade da arte, seja para construir sua própria teoria. Por isso encontramos tantos exemplos de pares de indiscerníveis tanto no seu artigo seminal "O Mundo da Arte" como, em fôlego maior, em Transfiguração do Lugar-comum. Em geral, ele constrói o experimento de duas formas diferentes, dependendo da classe de objetos indiscerníveis que ele contrasta: primeiro, contrastando um objeto comum aparentemente idêntico a outro objeto pertencente à classe das obras de arte, e, em seguida, contrastando dois objetos aparentemente idênticos, ambos pertencentes à classe das obras de arte, porém consideradas obras de arte diferentes. Ao contrastar esses objetos, pode-se aplicar o que Danto chama de "pergunta subtracionista", isto é, perguntar o que ficaria quando se subtraísse uma mera coisa comum de uma obra de arte, ou mesmo, perguntar o que ficaria se se subtraísse de duas obras de arte aparentemente idênticas as suas partes materiais. Danto procede, como aponta David Carrier9, do seguinte modo: 1) Apresenta dois estados de coisas ou duas coisas aparentemente idênticas; 2) demonstra que a diferença existente entre as duas coisas ou

8 DANTO. A. C. A Transfiguração do Lugar-comum. Tradução:Vera Pereira. São Paulo: Cosac Naify, 2005, p. 109.

9 CARRIER, D. "Danto as Systematic Philosopher or comme on lit Danto em français". In. ROLLINS, M (Ed.). Danto and his Critics. Oxford: Blackwell, 1993. 
estados de coisas não pode ser estabelecida pelas teorias essencialistas concorrentes; e, 3) propõe sua teoria como a melhor explicação acerca da razão porque dois objetos idênticos podem pertencer a classes distintas, sendo um objeto uma obra de arte e o outro um objeto comum.

Todavia, este modelo de argumentação fundamentado em pares indiscerníveis e a importância teórica dada a estes pela estética atual não está livre de críticas, por mais difundida que ela seja hoje. Carrier aponta impedimentos ao quadro dos indiscerníveis como narrado por seu arauto Danto. De acordo com ele,

Danto quer identificar as estruturas do mundo, como elas podem ser descritas pela filosofia, e esta, ele afirma, envolve descobrir que pode haver esses estados de cosias ou coisas que parecem idênticas, mas na verdade não o são. Mas esta afirmação de identidade/não-identidade, e a afirmação de que tais indiscerníveis existem, depende, de sua narrativa. É apenas em seu texto que descobrimos primeiramente a aparente identidade e que, em seguida, não é idêntica de fato. No fim descobrirmos a diferença entre o que parecia ser (...) arte e o que realmente $o$ é. Parece estranho concluir que essas diferenças são aspectos do mundo, não de uma maneira peculiar em que Danto o descreve. $O$ argumento de Danto depende de limitar e enquadrar nosso conhecimento [dos pares indiscernível] (...). Danto conta parte da estória, extrai uma conclusão que acaba sendo muito apressada, e então termina sua narrativa filosófica mostrando também as consequências de suas conclusões apressadas 10.

A argumentação de Carrier talvez forneça o suficiente para indicar que os indiscerníveis, como problematizado por Danto, desempenham mais uma função retórica do que propriamente uma descrição acurada dos estados de coisas, ou, para usar uma expressão de John Dewey, da experiência da obra de arte. E, já que trouxemos Dewey para conversa, a acusação de Carrier ao uso 
retórico dos pares indiscerníveis vai ao encontro, em alguns aspectos, do que o filósofo pragmatista chamou de "falácia da ênfase seletiva".

Segundo o pragmatista, as teorias tradicionais fragmentariam a experiência e cada uma delas daria ênfase a um pedaço ou fase da experiência, de modo que essa parte selecionada passaria a ser mais fundamental do que todas as outras que compõe a experiência. No caso de Danto, e dos demais que se valeram dos indiscerníveis, o que foi enfatizado, em geral, é uma situação de confusão epistêmica ou perceptiva, que levaria a postular que, em essência, a arte é "significado corporificado" ou alguma forma de percepção especial. Tais cenários atomizam ou o sujeito ou a obra de arte. James Guinlock, comentador de Dewey, poderia chamar esse cenário criado dos indiscerníveis de um "abuso da experiência" e diria, ecoando Carrier,

[que] os filósofos se tornam preocupados (...) apenas com uma fase da experiência, a que eles tentam analisar isolada de suas fases relacionadas. Assim, com base na experiência isolada, conceitos e distinções são desenvolvidos e são eles mesmos subsequentemente confundidos com objetos de estudo primário. O resultado é que o que é genuinamente primário é separado da "realidade" presumidamente referida por essas distinções, que são, portanto, incapazes de descrever em sua integridade primária aquela experiência a partir da qual elas inicialmente surgiram 11.

O isolamento das fases ou a fragmentação da experiência resultaria em assumir, por exemplo, a separação entre artístico e estético, arte e moral ou político, Arte (com "A" maiúsculo) e arte popular; ao invés de uma visão mais abarcante da arte. E é em razão disso que Dewey inicia Arte como Experiência com a seguinte frase atordoante: "Por uma das perversidades irônicas que muitas vezes acompanham o curso dos acontecimentos, a existência das obras de arte das quais dependem a formação de uma teoria estética se tornou um

11 GOUINLOCK, J. Jonh Dewey's Philosophy of Value. New York: Humanities Press, 1972, p. 31 (Tradução nossa). 
empecilho sobre elas"12. Esta frase inicia também o capítulo "Criatura viva", no qual Dewey intenciona demonstrar a continuidade entre as formas refinadas de experiências, no caso, as obras de artes, e as experiências primárias biológicas e cotidianas. Estabelecer esta continuidade é parte de um projeto mais amplo de ressignificação da experiência; do qual também faz parte o seu método da experiência, e nele reside sua função terapêutica. Este visa esburgar "certos conceitos modernos de experiência [que] serviriam, na verdade, para tornar nossa experiência ininteligível"13. Dewey visa, sobretudo, recuperar a integralidade da experiência.

Ora, onde queria chegar com isto tudo? Minha intenção é responder uma questão apresentada por Jackson: será a estética filosófica de Dewey datada? É fato que Dewey não aborda em Arte como Experiência, de 1932, muita da arte contemporânea na publicação desta obra, principalmente, o dadaísmo; embora recorra a Cézanne e a Matisse. E isto parece ainda mais estranho, poderia ser comentado, pelo fato de Dewey defender uma reaproximação entre arte e vida, e a Fonte seria um bom exemplo senão da aproximação, de completa indistinção. Mas aí incidiria um erro. A revitalização da relação entre arte e vida, para Dewey, tem a ver mais com a função social da arte, empalidecida em decorrência de nossa herança moderna e pela nossa estrutura socioeconômica, do que com uma indiferenciação ontológica. problema que segue ao encalço da questão acerca da atualidade de Dewey é outro, e diz respeito à possibilidade de se a sua estética pragmatista conseguiria lidar com casos de pares indiscerníveis, problema não enfrentado em Arte como Experiência.

Responder a essa pergunta, contudo, não é responder à questão posta por Danto: o que distinguiria uma obra de arte de um objeto fisicamente idêntico? Responder a esta pergunta seria aceitar prontamente o cenário e a narrativa de Danto, e, juntamente, a sua ideia de filosofia como sistemática e representacional. Quando ele diz que "de algum modo as questões sobre a arte

12 DEWEY, J. Arte como Experiência. Tradução: Vera Ribeiro. São Paulo: Martins Fontes, 2012, p. 59.

13 GOUINLOCK, J. Jonh Dewey's Philosophy of Value. New York: Humanities Press, 1972, p. 16 (Tradução nossa). 
estão próximas às questões que Descartes levantou acerca da diferença entre o sonho e a vigília14", ele deixa bem explícita a influência dos dualismos modernos em sua filosofia bem como o papel da criação de narrativas ou cenários para se extrair conclusões filosóficas.

Respondê-la, poderíamos pensar com Dewey, é dissolver esse problema. É evidenciar que este problema só surge quando se restringe a experiência; e essa limitação é manifesta nos usos retóricos das narrativas e cenários utilizados por Danto e outros. É denunciar quando se aceita de antemão que certos tipos de experiências são mais fundamentais do que outras. É ver como a arte entra na nossa experiência considerada em sua forma mais abrangente, e não apenas em sua parte formal ou institucional, histórica, ou qualquer outra.

Isto que quero dizer com ressignificação de Dewey: embora sua filosofia seja datada num sentido (o estar condicionada a seu tempo), hoje é, como foi antes, ferramenta de grande valia. Seja em sua função terapêuticas de dissolver os caroços dualistas da filosofia moderna que ainda desandam os problemas filosóficos, seja por nos fazer prestar mais atenção na experiência em que está a obra de arte.

\section{REFERÊNCIAS:}

CARRIER, D. "Danto as Systematic Philosopher or comme on lit Danto em français". In. ROLLINS, M (Ed.). Danto and his Critics. Oxford: Blackwell, 1993. CLIVE, B. "A Hipótese Estética". Tradução: Vítor Silva. In: D'OREY, C. (Org.) O que é a arte? Uma perspectiva analítica. Lisboa, Dinalivro, 2007 (p. 27-44). DANTO. A. C. A Transfiguração do Lugar-comum. Tradução:Vera Pereira. São Paulo: Cosac Naify, 2005.

14 DANTO. A. C. Connecions to the World: the basic concepts of philosophy. Berkeley: University of California Press, 1997, p.xv. (Tradução nossa). 
DANTO. A. C. Connecions to the World: the basic concepts of philosophy. Berkeley: University of California Press, 1997.

DANTO, A. C. "O Mundo da Arte". Tradução: Vítor Silva. In: D'OREY, C. (Org.) O que é a arte? Uma perspectiva analítica. Lisboa, Dinalivro, 2007 (p. 79 100).

DEWEY, J. Arte como Experiência. Tradução: Vera Ribeiro. São Paulo: Martins Fontes, 2012.

DICKIE, G. "O que é a Arte?". Tradução: Vítor Silva. In: D'OREY, C. (Org.) O que é a arte? Uma perspectiva analítica. Lisboa, Dinalivro, 2007 (p. 101-118). GOUINLOCK, J. Jonh Dewey's Philosophy of Value. New York: Humanities Press, 1972.

KENNICK, W. E. "Does tradicional aesthetics rest on a mistake?". Mind Vol. LXVII $n^{\circ} 267$. (1958), p. 317-334.

STOLNITZ, J. "A Atitude Estética". Tradução: Vítor Silva. In: D'OREY, C. (Org.) O que é a arte? Uma perspectiva analítica. Lisboa, Dinalivro, 2007 (p. 45-60). WEITZ, M. "O Papel da Teoria na Estética". Tradução: Vítor Silva. In: D'OREY, C. (Org.) O que é a arte? Uma perspectiva analítica. Lisboa, Dinalivro, 2007 (p. 61-78). 